\title{
Hand and Oral Hygiene Practices among Adolescents in Dominican Republic, Suriname and Trinidad and Tobago: Prevalence, Health, Risk Behavior, Mental Health and Protective Factors
}

\author{
Supa Pengpid ${ }^{1,2}$ and Karl Peltzer ${ }^{3, *}$ (i) \\ 1 ASEAN Institute for Health Development, Mahidol University, Salaya 73170, Thailand; \\ supaprom@yahoo.com \\ 2 Department of Research Administration and Development, University of Limpopo, \\ Sovenga 0727, South Africa \\ 3 Department of Psychology, University of the Free State, Bloemfontein 9300, South Africa \\ * Correspondence: kfpeltzer@gmail.com
}

Received: 28 September 2020; Accepted: 24 October 2020; Published: 27 October 2020

\begin{abstract}
Objective: The study aimed to estimate the prevalence and correlates of oral hygiene $(\mathrm{OH})$ and hand hygiene $(\mathrm{HH})$ behavior among school adolescents in three Caribbean countries. Method: In all, 7476 school adolescents (median age 14 years) from the Dominican Republic, Suriname, and Trinidad and Tobago responded to the cross-sectional Global School-Based Student Health Survey (GSHS) in 2016-2017. Results: The prevalence of poor OH (tooth brushing < 2 times/day) was 16.9\%, poor $\mathrm{HH}$ (not always before meals) was $68.2 \%$, poor $\mathrm{HH}$ (not always after toilet) was $28.4 \%$, and poor $\mathrm{HH}$ (not always with soap) was $52.7 \%$. In the adjusted logistic regression analysis, current cannabis use, inadequate fruit and vegetable intake, poor mental health, and low parental support increased the odds for poor $\mathrm{OH}$. Rarely or sometimes experiencing hunger, trouble from alcohol use, inadequate fruit and vegetable intake, poor mental health, and low parental support were associated with poor $\mathrm{HH}$ (before meals and/or after the toilet, and/or with soap). Conclusion: The survey showed poor $\mathrm{OH}$ and $\mathrm{HH}$ behavior practices. Several sociodemographic factors, health risk behaviors, poor mental health, and low parental support were associated with poor $\mathrm{OH}$ and/or $\mathrm{HH}$ behavior that can assist with tailoring $\mathrm{OH}$ and $\mathrm{HH}$ health promotion.
\end{abstract}

Keywords: oral hygiene; hand hygiene; school adolescents; correlates; Caribbean

\section{Introduction}

Oral hygiene $(\mathrm{OH})$ ("tooth brushing $\geq 2 /$ day") is a major tool to prevent and control periodontal diseases and dental caries [1]. Good hand hygiene $(\mathrm{HH})$ using soap can "avert 0.5-1.4 million deaths every year" [2]. Despite the potential positive impact of good $\mathrm{OH}$ and $\mathrm{HH}$, the prevalence of good $\mathrm{OH}$ and $\mathrm{HH}$ practices among adolescents is low [3-8]. There is a lack of recent national information on $\mathrm{OH}$ and $\mathrm{HH}$ among adolescents in Caribbean countries, such as the Dominican Republic, Suriname, and Trinidad and Tobago [4]. Among school adolescents in 15 Latin American and Caribbean countries from 2006-2011, 2-9\% reported infrequent (<one time/day) tooth brushing and 2-7\% infrequent (never or rarely) $\mathrm{HH}$ after toilet use [4]. In the Dominican Republic, "risk factors for diarrhea and cholera transmission include poor adherence to water, sanitation, and hygiene (WASH) practices such as consistent hand washing" [9-11]. In Suriname, the prevalence of caries in schoolchildren was moderate to high (using WHO criteria), and the majority of children had dental caries [12]. The prevalence of tooth-cleaning ( $\geq 2$ times/day) among adults in the Dominican Republic was 94.2\% [13]. 
In a multi-country investigation among school adolescents, most of the respondents (80\%) reported daily tooth brushing, and more than one in 20 students brushed their teeth "less than once a day or never" in half of the countries [5], including 10.0\% in Zambia [14]. In a study among school-going adolescents in nine African countries, the results showed that $22.7 \%$ had poor $\mathrm{OH}$ (tooth brushing $<2 /$ day), $62.2 \%$ had poor $\mathrm{HH}$ (not always before meals), $58.4 \%$ had poor $\mathrm{HH}$ (not always after toilet), and $35.0 \%$ had poor HH (not always with soap) [15], whereas in six Southeast Asian countries, 17.1\% had poor $\mathrm{OH}, 44.8 \%$ had poor $\mathrm{HH}$ (before meals), $31.9 \%$ had poor $\mathrm{HH}$ (after toilet), and $55.8 \%$ had poor $\mathrm{HH}$ (with soap) [3].

As reviewed earlier [3], "factors associated with poor $\mathrm{OH}$ among adolescents include sociodemographic variables (early adolescence, male sex, and lower wealth status), health risk behaviours (insufficient fruit and vegetable consumption, physical inactivity, and tobacco use), poor mental health and lack of parental support". Factors associated with poor HH among adolescents [3], include "male sex, lower wealth status, health risk behaviours (low fruit and vegetable consumption, sedentary behaviour and physical inactivity, and substance use), poor mental health, and lack of parental support".

Recent national data on the prevalence and correlates of $\mathrm{OH}$ and $\mathrm{HH}$ among adolescents are lacking in the Caribbean region. Therefore, the aim of this study was to assess the prevalence of $\mathrm{OH}$ and $\mathrm{HH}$ in three Caribbean countries. We looked at sociodemographic factors, health risk behaviors, and protective factors of poor $\mathrm{OH}$ and $\mathrm{HH}$ among adolescents in the Dominican Republic, Suriname, and Trinidad and Tobago in 2016-2017.

\section{Methods}

\subsection{Sample and Procedures}

Cross-sectional nationally representative survey data from the 2016 Dominican Republic, 2016 Suriname, and 2017 Trinidad and Tobago Global School-Based Student Health Survey (GSHS) were analyzed [16]. The sampling approach included a two-stage sampling design, including schools and classes. All school students present in a selected classroom were eligible to participate by filling in a self-administered anonymous questionnaire [16]. Information that was more detailed can be publically accessed [16]; the overall response rate was 63\% in the Dominican Republic, 83\% in Suriname, and 89\% in Trinidad and Tobago [16]. Ethical approval was obtained from the ethics committees in each study country, and participants gave written consent [16].

\subsection{Measures}

The GSHS questions used [16] are described in Supplementary Table S1.

Oral hygiene was sourced from the question, "During the past 30 days, how many times per day did you usually clean or brush your teeth?" Responses ranged from " $1=$ I did not clean or brush my teeth during the past 30 days to $4=6$ or more times per day (coded $1-3=1$ and $4-6=0$ )".

Hand hygiene was sourced from three items. "During the past 30 days, how often did you wash your hands before eating/after using the toilet or latrine/use soap?" Response options ranged from " $1=$ never to $5=$ always $($ coded $1-4=1$ and $5=0)$ ".

Sociodemographic information included country, sex, age, and experiences of hunger (as a proxy for economic status).

Health risk behaviors assessed included current tobacco use, trouble from alcohol use, current cannabis use, fruit and vegetable consumption, leisure-time sedentary behavior, physical activity, and attendance of physical education classes.

Poor mental health was defined as " $0=0$ low, $1=1$ medium, and $2-5=2$ high based on positive responses to the items no close friends, loneliness, anxiety, suicidal ideation and suicide attempt" [3]. Protective factors included school attendance, peer, and parental support. "The four items on parental 
or guardian support were summed and classified into three groups, 0-1 low, 2 medium, and 3-4 high support" [3].

\subsection{Data Analysis}

Statistical analyses were conducted with STATA software version 15 (Stata Corporation, College Station, TX, USA), taking into account the sampling weights and multistage sampling design. Multivariable logistic regression analyses were used to predict the covariates of poor $\mathrm{OH}$ (tooth brushing <2/day), poor $\mathrm{HH}$ (not always before meals), poor $\mathrm{HH}$ (not always after toilet), and poor $\mathrm{HH}$ (not always with soap). Missing variable information was excluded from the analysis and $p$-values $<0.05$ indicated statistical significance.

\section{Results}

\subsection{Sample Characteristics and Hygiene Behavior}

The study sample comprised 7476 school adolescents (14 years median age; interquartile range $=13-16$ ) from the Dominican Republic, Suriname and Trinidad and Tobago. In all three countries, the prevalence of poor $\mathrm{OH}$ (<twice a day tooth brushing) was $16.9 \%$, poor $\mathrm{HH}$ (not always before meals) was $68.2 \%$, poor $\mathrm{HH}$ (not always after toilet) was $28.4 \%$, and poor $\mathrm{HH}$ (not always with soap) was $52.7 \%$ (see Table 1 ).

Table 1. Characteristics of the sample and hygiene behavior in the Dominican Republic, Suriname, and Trinidad and Tobago, 2016-2017.

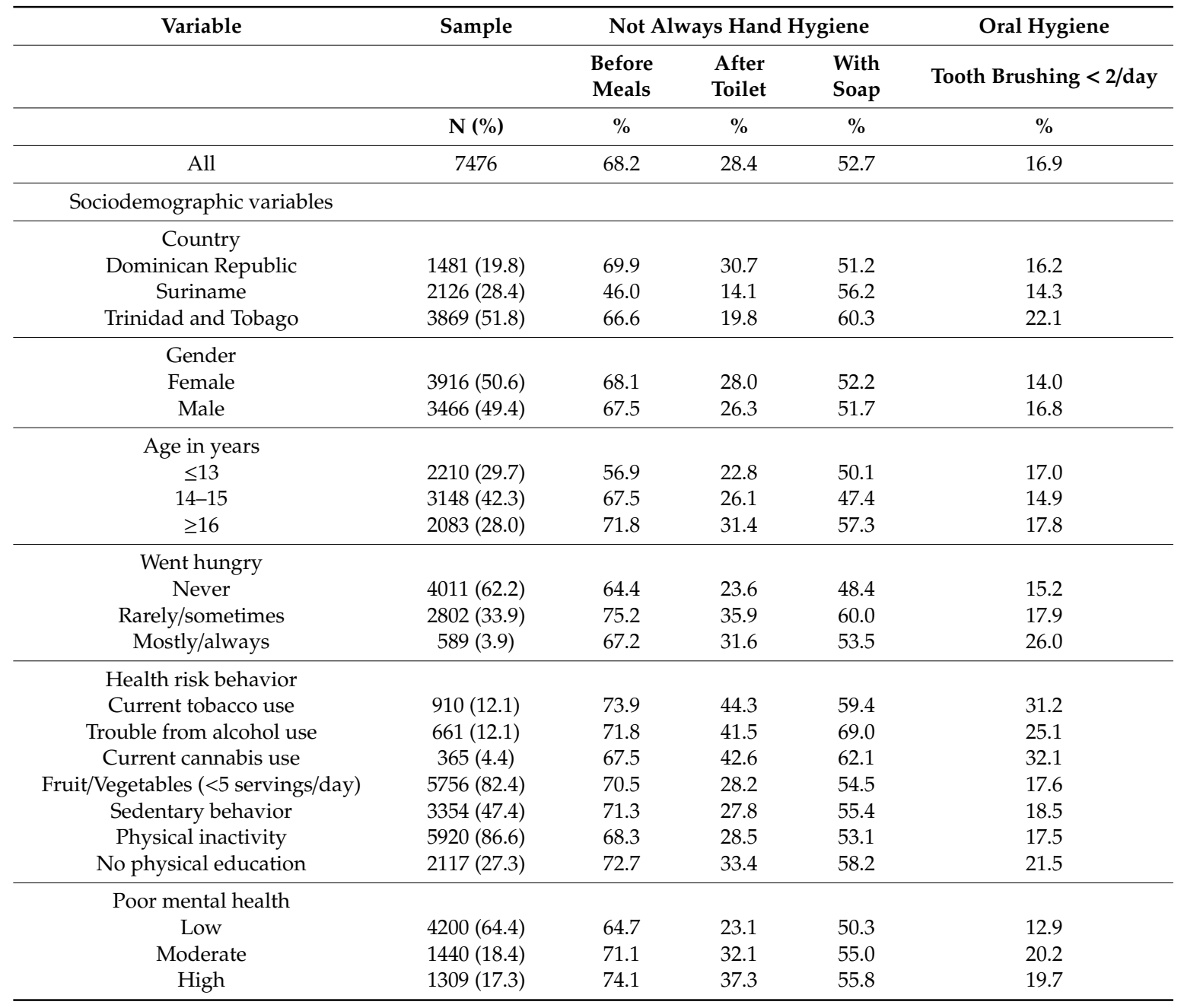


Table 1. Cont.

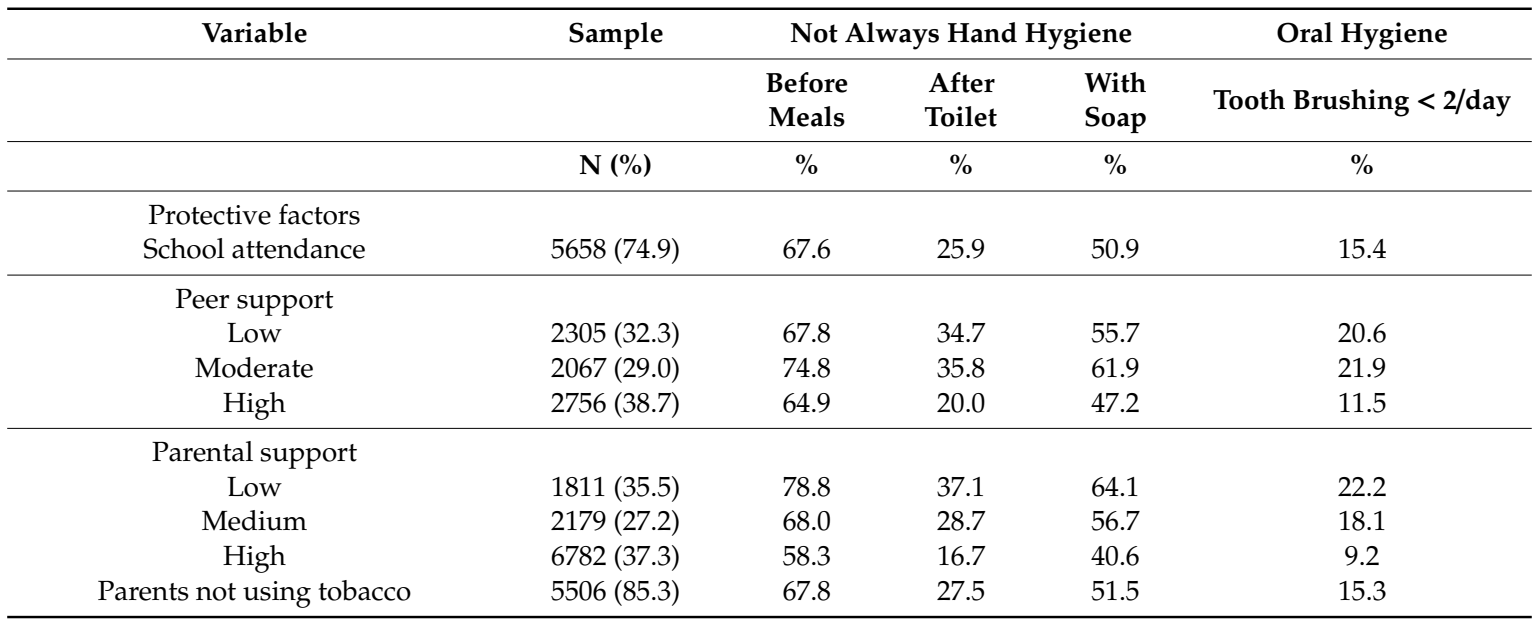

\subsection{Associations with Poor Oral and Hand Hygiene}

In adjusted logistic regression analysis, students from Trinidad and Tobago (adjusted odds ratio (AOR): 1.63 , 95\% confidence interval (CI): 1.23-2.14), current cannabis use (AOR: $2.41,95 \%$ CI: 1.31-4.45), inadequate fruit and vegetable intake (AOR: 2.24, 95\% CI: 1.02-4.93), and high poor mental health (AOR: $1.39,95 \%$ CI: 1.00-1.91) increased the odds, and high parental support (AOR: 0.70, 95\% CI: 0.51-0.97) decreased the odds for poor oral hygiene.

Compared to students from the Dominican Republic, students from Suriname and Trinidad and Tobago had lower odds for poor HH before meals and after the toilet, but higher odds for using soap. The male sex had lower odds for poor $\mathrm{HH}$ after the toilet, and older adolescents had higher odds for poor HH with soap. Rarely or sometimes experiencing hunger was positively, and high parental support was negatively associated with all three poor HH indicators (before meals, after the toilet, and with soap). Inadequate fruit and vegetable intake and moderate peer support were associated with poor $\mathrm{HH}$ after meals and with soap, whereas moderate or high poor mental health increased the odds for poor $\mathrm{HH}$ after meals and after toilet. Trouble from alcohol use was positively associated with poor $\mathrm{HH}$ with soap, and physical inactivity and sedentary behavior were negatively associated with poor $\mathrm{HH}$ after toilet (see Table 2).

Table 2. Associations with poor oral hygiene $(\mathrm{OH})$ and poor hand hygiene $(\mathrm{HH})$ indicators.

\begin{tabular}{|c|c|c|c|c|}
\hline Variable & Poor OH & $\begin{array}{c}\text { Poor HH } \\
\text { (before Meals) }\end{array}$ & $\begin{array}{c}\text { Poor HH } \\
\text { (after Toilet) }\end{array}$ & $\begin{array}{c}\text { Poor HH } \\
\text { (with Soap) }\end{array}$ \\
\hline & AOR (CI 95\%) & AOR (CI 95\%) & AOR (CI 95\%) & AOR (CI 95\%) \\
\hline \multicolumn{5}{|l|}{$\begin{array}{l}\text { Sociodemographic } \\
\text { variables }\end{array}$} \\
\hline \multicolumn{5}{|l|}{ Country } \\
\hline Dominican Republic & 1 (Reference) & 1 (Reference) & 1 (Reference) & 1 (Reference) \\
\hline Suriname & $1.09(0.72,1.64)$ & $0.31(0.25,0.37)^{* * *}$ & $0.29(0.20,0.42)^{* * *}$ & $1.34(1.13,1.59)^{* * *}$ \\
\hline Trinidad and Tobago & $1.63(1.23,2.14)^{* * *}$ & $0.77(0.61,0.97)$ * & $0.41(0.31,0.55)^{* * *}$ & $1.43(1.13,1.82)^{* *}$ \\
\hline \multicolumn{5}{|l|}{ Gender } \\
\hline Female & 1 (Reference) & 1 (Reference) & 1 (Reference) & 1 (Reference) \\
\hline Male & $0.95(0.66,1.37)$ & $0.81(0.54,1.21)$ & $0.76(0.58,0.98)$ * & $0.83(0.63,1.09)$ \\
\hline \multicolumn{5}{|l|}{ Age in years } \\
\hline$\leq 13$ & 1 (Reference) & 1 (Reference) & 1 (Reference) & 1 (Reference) \\
\hline $14-15$ & $1.10(0.69,1.73)$ & $1.38(0.98,1.93)$ & $1.07(0.78,1.47)$ & $0.96(0.69,1.34)$ \\
\hline$\geq 16$ & $0.95(0.71,1.26)$ & $1.57(1.00,2.47)$ & $1.21(0.75,1.97)$ & $1.57(1.04,2.38)^{*}$ \\
\hline
\end{tabular}


Table 2. Cont.

\begin{tabular}{|c|c|c|c|c|}
\hline Variable & Poor $\mathrm{OH}$ & $\begin{array}{c}\text { Poor HH } \\
\text { (before Meals) }\end{array}$ & $\begin{array}{c}\text { Poor HH } \\
\text { (after Toilet) }\end{array}$ & $\begin{array}{c}\text { Poor HH } \\
\text { (with Soap) }\end{array}$ \\
\hline & AOR (CI 95\%) & AOR (CI 95\%) & AOR (CI 95\%) & AOR (CI 95\%) \\
\hline \multicolumn{5}{|l|}{ Went hungry } \\
\hline Never & 1 (Reference) & 1 (Reference) & 1 (Reference) & 1 (Reference) \\
\hline Rarely/sometimes & $1.11(0.80,1.52)$ & $1.51(1.25,1.84)^{* * *}$ & $2.04(1.67,2.49)^{* * *}$ & $1.40(1.02,1.93)$ * \\
\hline Mostly/always & $1.72(0.85,3.49)$ & $0.94(0.57,1.54)$ & $1.75(0.73,4.19)$ & $1.35(0.76,2.41)$ \\
\hline \multicolumn{5}{|l|}{ Health risk behavior } \\
\hline Current tobacco use & $0.83(0.56,1.23)$ & $0.89(0.52,1.55)$ & $0.81(0.95,2.49)$ & $0.73(0.46,1.16)$ \\
\hline Trouble from alcohol use & $1.09(0.55,2.19)$ & $1.03(0.61,1.75)$ & $1.31,0.78,2.20)$ & $2.05(1.17,3.25)$ * \\
\hline Current cannabis use & $2.41(1.31,4.45)^{* *}$ & $0.60(0.24,1.52)$ & $1.05(0.24,4.57)$ & $1.25(0.42,3.69)$ \\
\hline $\begin{array}{l}\text { Fruit/Vegetables } \\
\text { (<5 servings/day) }\end{array}$ & $2.24(1.02,4.93) *$ & $1.69(1.27,2.25)^{* * *}$ & $1.18(0.83,1.67)$ & $1.53(1.01,2.32) *$ \\
\hline Sedentary behavior & $0.89(0.62,1.28)$ & $1.07(0.87,1.32)$ & $0.62(0.42,0.91) *$ & $1.03(0.85,1.26)$ \\
\hline Physical inactivity & $1.12(0.86,1.48)$ & $0.73(0.49,1.10)$ & $0.65(0.51,0.82)^{* * *}$ & $0.81(0.52,1.27)$ \\
\hline No physical education & $1.11(0.77,1.62)$ & $1.10(0.72,1.68)$ & $0.98(0.66,1.47)$ & $1.02(0.64,1.61)$ \\
\hline \multicolumn{5}{|l|}{ Poor mental health } \\
\hline Low & 1 (Reference) & 1 (Reference) & 1 (Reference) & 1 (Reference) \\
\hline Moderate & $1.22(0.82,1.83)$ & $1.38(1.03,1.86)^{*}$ & $1.51(0.89,2.57)$ & $1.00(0.73,1.36)$ \\
\hline High & $1.39(1.00,1.91) *$ & $1.37(0.95,1.97)$ & $1.69(1.30,2.18)^{* * *}$ & $0.87(0.59,1.29)$ \\
\hline \multicolumn{5}{|l|}{ Protective factors } \\
\hline School attendance & $0.84(0.47,1.50)$ & $1.10(0.85,1.43)$ & $0.81(0.61,1.07)$ & $0.89(0.76,1.05)$ \\
\hline \multicolumn{5}{|l|}{ Peer support } \\
\hline Low & 1 (Reference) & 1 (Reference) & 1 (Reference) & 1 (Reference) \\
\hline Moderate & $0.97(0.72,1.32)$ & $1.73(1.27,2.34)^{* * *}$ & $1.13(0.69,1.85)$ & $1.47(1.01,2.15) *$ \\
\hline High & $0.79(0.42,1.49)$ & $1.39(0.90,2.13)$ & $0.87(0.55,1.38)$ & $1.17(0.81,1.68)$ \\
\hline \multicolumn{5}{|l|}{ Parental support } \\
\hline Low & 1 (Reference) & 1 (Reference) & 1 (Reference) & 1 (Reference) \\
\hline Medium & $1.19(0.81,1.52)$ & $0.61(0.39,0.95) *$ & $0.91(0.68,1.21)$ & $0.94(0.62,1.43)$ \\
\hline High & $0.70(0.51,0.97)$ * & $0.37(0.28,0.50)^{* * *}$ & $0.49(0.33,0.73)^{* * *}$ & $0.51(0.37,0.70)^{* * *}$ \\
\hline Parents not using tobacco & $1.10(0.60,2.02)$ & $0.76(0.55,1.04)$ & $0.91(0.65,1.28)$ & $0.88(0.71,1.09)$ \\
\hline
\end{tabular}

\section{Discussion}

This study gives an insight on important health preventive behaviors such as $\mathrm{OH}$ and $\mathrm{HH}$ in three Caribbean countries. The prevalence of poor $\mathrm{OH}(16.9 \%)$ seemed similar in six countries in Southeast Asia (17.1\%) [3], lower in African countries (22.7\%) [15], and lower in three countries in Oceania (22-38\%) [17]. The prevalence of poor HH (before meals) (68.2\%) was higher in nine countries in Africa (37.8\%) [15], six Southeast Asian countries (44.8\%) [3], and Pacific island states (30\% to 35\%) [17]. Poor HH (after toilet) (28.4\%) was similar to the Southeast Asian study (31.9\%) [3], but lower than in nine African countries (41.6\%) [15]. Poor HH (with soap) (52.7\%) was lower than in African countries (65.0\%) [15], but similar to Southeast Asian countries (55.8\%) [3].

Poor $\mathrm{OH}$ was significantly higher in Trinidad and Tobago (22.1\%) than in the Dominican Republic $(16.2 \%)$, poor $\mathrm{HH}$ (before meals) was the highest among adolescents in the Dominican Republic, and poor HH (after toilet) was the highest in the Dominican Republic (30.7\%), whereas poor $\mathrm{HH}$ (with soap) was the highest in Trinidad and Tobago (60.3\%) in this study. The higher prevalence of poor HH (after toilet) in the Dominican Republic may be attributed to the lowest access to improved water sources and sanitation facilities (86\%), compared to Suriname $(93 \%)$, and Trinidad and Tobago (94\%) [18]. The prevalence of poor HH (with soap) was the highest in Trinidad and Tobago (60.3\%), followed by Suriname (56.2\%), and the Dominican Republic (51.2\%), whereas based on national household surveys, the "percentage of households with a specific place for hand washing where water and soap or other cleansing agent are present" was the highest in Trinidad and Tobago (94.6\%) [19], followed by Suriname (80.1\%) [20], and the Dominican Republic (56.1\%) [21]. The national coverage 
estimate for water and sanitation in schools was $80 \%$ for water and $65 \%$ for sanitation in Suriname, and $100 \%$ for water and $100 \%$ for sanitation in Trinidad and Tobago [22]. It is possible that poorer $\mathrm{HH}$ among adolescents in Trinidad and Tobago is related to the poor implementation of the Health and Family Life Education (HFLE) school health program, which includes personal hygiene [23].

While some previous research $[3,5,15,24,25]$ showed a positive association between the male sex and poor $\mathrm{OH}$ and/or poor $\mathrm{HH}$, this survey did not find significant sex differences, apart from the male sex being negatively associated with poor $\mathrm{HH}$ (after the toilet). In a study among adolescents in Zambia, the male sex was negatively associated with poor OH [11]. Compared to students who were never hungry, students who were rarely or sometimes hungry had higher odds for poor $\mathrm{HH}$ (before meals, after the toilet, and with soap). This result was in line with former studies $[7,14,17,26,27]$ as it showed an association between lower economic status (experience of hunger) and poor $\mathrm{OH}$ and/or poor HH. It is possible that adolescents from poorer households have less access to toothbrushes and/or soap.

Consistent with previous studies $[3,6,8,14,15,17,28]$, this survey showed a positive association between health risk behaviors (current cannabis use, trouble from alcohol use, and inadequate fruit and vegetable intake), poor mental health, and lack of parental support with poor $\mathrm{OH}$ and/or poor $\mathrm{HH}$ (before meals, and/or after the toilet, and/or with soap). "It is possible that fruit and vegetable consumption, which is known to have positive effects on well-being, acts as mediators in the correlation between poor mental health and personal hygiene" [8]. Contrary to results from previous studies $[3,15,17,24]$, physical inactivity and sedentary behavior were negatively associated with poor $\mathrm{HH}$ (after the toilet), and moderate peer support was associated with poor $\mathrm{HH}$ (before meals and with soap). Despite this, other health risk behaviors (current cannabis use, trouble from alcohol use, and inadequate fruit and vegetable intake) seemed to cluster with poor $\mathrm{OH}$ and/or poor $\mathrm{HH}[3,4,26,29]$. Health promotion programs should promote "hand-washing with soap and tooth brushing with tooth paste," together with the identified clustering health risk behaviors and poor mental health, to prevent dental conditions and infectious diseases, such as diarrhea and cholera, in Caribbean countries $[2,9-11,30,31]$.

\section{Limitations}

The study focused only on school adolescents and was cross-sectional in design. Furthermore, the self-report of the data, including $\mathrm{OH}$ and $\mathrm{HH}$, could have biased responses. Yet, self-reported measures of $\mathrm{OH}$ have been used as a proxy tool for reporting indicators of clinical $\mathrm{OH}$ among adolescents [32]. The difficulty of comparing the prevalence rates of poor $\mathrm{HH}$ is that different definitions have been used, e.g., never or rarely (rather than sometimes, most of the time, or always) washing hands after toilet use $[4,8]$, and not always (never, rarely, sometimes, or most of the time) washing hands after toilet use $[3,15,17,24]$.

\section{Conclusions}

This study, including three national surveys among school adolescents in the Caribbean in 2016-2017, showed a high proportion of poor $\mathrm{OH}$ (<twice a day tooth brushing) $(16.9 \%)$, poor $\mathrm{HH}$ (not always before meals) $(68.2 \%)$, poor $\mathrm{HH}$ (not always after toilet) $(28.4 \%)$, and poor $\mathrm{HH}$ (not always with soap) (52.7\%). Several sociodemographic factors, health risk behaviors, poor mental health, and low parental support were associated with poor $\mathrm{OH}$ and/or poor $\mathrm{HH}$ behavior that can assist with tailoring $\mathrm{OH}$ and $\mathrm{HH}$ health promotion.

Supplementary Materials: The following are available online at http://www.mdpi.com/1660-4601/17/21/7860/s1, Table S1: Description of study variables.

Author Contributions: Conceptualization, S.P. and K.P.; methodology, S.P.; formal analysis, K.P and S.P.; writing — original draft preparation, S.P.; writing — review and editing, K.P; All authors have read and agreed to the published version of the manuscript.

Funding: This research received no external funding. 
Acknowledgments: The data source, the World Health Organization NCD Microdata Repository (URL: https: //extranet.who.int/ncdsmicrodata/index.php/catalog), is hereby acknowledged.

Conflicts of Interest: The authors declare no conflict of interest.

\section{Abbreviations}

GSHS Global School-Based Student Health Survey;

$\mathrm{OH} \quad$ Oral hygiene;

HH Hand hygiene;

STATA Statistics and data.

\section{References}

1. Hayasaki, D.H.; Saitoh, D.I.; Nakakura-Ohshima, D.K.; Hanasaki, D.M.; Nogami, D.Y.; Nakajima, D.T.; Inada, D.E.; Iwasaki, D.T.; Iwase, D.Y.; Sawami, D.T.; et al. Tooth brushing for oral prophylaxis. Jpn. Dent. Sci. Rev. 2014, 50, 69-77. [CrossRef]

2. Curtis, V.; Cairncross, S. Effect of washing hands with soap on diarrhoea risk in the community: A systematic review. Lancet Infect. Dis. 2003, 3, 275-281. [CrossRef]

3. Pengpid, S.; Peltzer, K. Prevalence and associated factors of oral and hand hygiene behaviour among adolescents in six Southeast Asian countries. Int. J. Adolesc. Med. Health 2020. [CrossRef] [PubMed]

4. McKittrick, T.; Jacobsen, K.H. Oral Hygiene and Handwashing Practices among Middle School Students in 15 Latin American and Caribbean Countries. West Indian Med J. 2016, 64, 266-268. [CrossRef]

5. Nordhauser, J.; Rosenfeld, J. Adapting a water, sanitation, and hygiene picture-based curriculum in the Dominican Republic. Glob. Health Promot. 2019, 27, 6-14. [CrossRef]

6. Lund, A.J.; Keys, H.M.; Leventhal, S.; Foster, J.W.; Freeman, M.C. Prevalence of cholera risk factors between migrant Haitians and Dominicans in the Dominican Republic. Rev. Panam. Salud Públ. 2015, 37, 125-132.

7. McLennan, J.D. Prevention of diarrhoea in a poor District of Santo Domingo, Dominican Republic: Practices, knowledge, and barriers. J. Health Popul. Nutr. 2000, 18, 15-22.

8. Crombag, P.; Schuller, A.A. Prevalence of Caries among Schoolchildren in the Interior of Suriname. Am. J. Trop. Med. Hyg. 2018, 99, 1619-1624. [CrossRef]

9. Kahar, P. Patterns of oral hygiene behaviors, daily habits, and caries prevalence in India and dominican republic: A comparative study. Indian J. Dent. Res. 2019, 30, 87-93. [CrossRef]

10. McKittrick, T.R.; Jacobsen, K.H. Oral hygiene practices among middle-school students in 44 low- and middle-income countries. Int. Dent. J. 2014, 64, 164-170. [CrossRef]

11. Siziya, S.; Muula, A.S.; Rudatsikira, E. Self-reported poor oral hygiene among in-school adolescents in Zambia. BMC Res. Notes 2011, 4, 255. [CrossRef] [PubMed]

12. Pengpid, S.; Peltzer, K. Hygiene Behaviour and Associated Factors among In-School Adolescents in Nine African Countries. Int. J. Behav. Med. 2010, 18, 150-159. [CrossRef]

13. World Health Organization (WHO). Global School-Based Student Health Survey (GSHS). 2019. Available online: https://www.who.int/ncds/surveillance/gshs/en/ (accessed on 10 April 2020).

14. Tran, D.; Phongsavan, P.; E Bauman, A.; Havea, D.; Galea, G. Hygiene Behaviour of Adolescents in the Pacific: Associations with Socio-demographic, Health behaviour and School Environment. Asia Pac. J. Public Health 2006, 18, 3-11. [CrossRef] [PubMed]

15. Pan American Health Organization. Water and Sanitation: Evidence for Public Policies Focused on Human Rights and Public Health Results. 2011. Available online: https://www.paho.org/hq/dmdocuments/2012/ Water-Sanitation-final-eng.pdf (accessed on 7 August 2020).

16. UNICEF. Trinidad and Tobago. Multiple Indicator Cluster Survey 2011. 2017. Available online: https: //www.unicef.org/easterncaribbean/media/1221/file/ECA-Trinidad-2011-MICS-Report-2017.pdf (accessed on 7 August 2020).

17. UNICEF. Suriname: Multiple Indicator Cluster Survey 2018. 2019. Available online: https: //mics-surveys-prod.s3.amazonaws.com/MICS6/Latin\%20America\%20and\%20Caribbean/Suriname/ 2018/Survey\%20findings/Suriname\%202018\%20MICS\%20Survey\%20Findings\%20Report_English.pdf (accessed on 7 August 2020). 
18. UNICEF. Dominican Republic. Multiple Indicator Cluster Survey. 2014. Available online: https://mics-surveys-prod.s3.amazonaws.com/MICS5/Latin\%20America\%20and\%20Caribbean/ Dominican\%20Republic/2014/Final/Dominican\%20Republic\%202014\%20MICS_Spanish.pdf (accessed on 7 August 2020).

19. UNICEF; World Health Organization. Scoping Study: Are Data Available to Monitor the SDGs for WASH in Schools and Health Care Facilities in the Latin America and Caribbean Region? 2017. Available online: https://www.unicef.org/lac/media/3021/file/PDF\%20Scoping\%20study\%20Portada\%20Scoping\%20study. \%20Are \%20data\%20available\%20to\%20monitor\%20the\%20SDGs\%20for\%20WASH \%20in\%20schools\% 20and\%20health\%20care\%20facilities\%20in\%20LAC?pdf (accessed on 7 August 2020).

20. Onuoha, C.A.; Dyer-Regis Onuoha, P.C. Implementation Levels of a Life-Skill Based School Health Program in a Caribbean country. IJHSR 2017, 7, 353-359.

21. Peltzer, K.; Pengpid, S. Oral and Hand Hygiene Behaviour and Risk Factors among In-School Adolescents in Four Southeast Asian Countries. Int. J. Environ. Res. Public Health 2014, 11, 2780-2792. [CrossRef] [PubMed]

22. Sadinejad, M.; Kelishadi, R.; Qorbani, M.; Shahsanai, A.; Motlagh, M.E.; Ardalan, G.; Heshmat, R.; Keikha, M. A Nationwide Survey on Some Hygienic Behaviors of Iranian Children and Adolescents: The CASPIAN-IV Study. Int. J. Prev. Med. 2014, 5, 1083-1090.

23. Maes, L.; Vereecken, C.; Vanobbergen, J.; Honkala, S. Tooth brushing and social characteristics of families in 32 countries. Int. Dent. J. 2006, 56, 159-167. [CrossRef]

24. Park, Y.-D.; Patton, L.L.; Kim, H.-Y. Clustering of Oral and General Health Risk Behaviors in Korean Adolescents: A National Representative Sample. J. Adolesc. Health 2010, 47, 277-281. [CrossRef]

25. Dobe, M.; Mandal, R.N.; Jha, A. Social Determinants of Good Hand-Washing Practice (GHP) Among Adolescents in a Rural Indian Community. Fam. Community Health 2013, 36, 172-177. [CrossRef]

26. Zaborski, A.; Milciuviene, S.; Bendoraitiene, E.; Zaborskyte, A. Oral health behaviour of adolescents: A comparative study in 35 countries. Stomatologija 2004, 6, 44-50.

27. Slekiene, J.; Mosler, H.-J. Does depression moderate handwashing in children? BMC Public Health 2017, 18, 82. [CrossRef]

28. Ranasinghe, S.; Ramesh, S.; Jacobsen, K.H. Hygiene and mental health among middle school students in India and 11 other countries. J. Infect. Public Health 2016, 9, 429-435. [CrossRef] [PubMed]

29. Jordão, L.M.R.; Malta, D.C.; Freire, M.D.C.M. Simultaneidade de comportamentos de risco à saúde bucal em adolescentes: Evidência da Pesquisa Nacional de Saúde do Escolar. Rev. Bras. Epidemiol. 2018, 21. [CrossRef] [PubMed]

30. Buunk-Werkhoven, Y.A. Effects and Benefits of a Program to Promote Tooth Brushing among 12-Year-Old School Children in the Dominican Republic. Adv. Dent. Oral Health 2019, 10, 1-6. [CrossRef]

31. Petersen, P.E.; Bourgeois, D.; Ogawa, H.; Estupinan-Day, S.; Ndiaye, C. The global burden of oral diseases and risks to oral health. Bull. World Health Organ. 2005, 83, 661-669. [PubMed]

32. Gil, G.S.; Morikava, F.S.; Santin, G.C.; Pintarelli, T.P.; Fraiz, F.C.; Ferreira, F.M. Reliability of self-reported toothbrushing frequency as an indicator for the assessment of oral hygiene in epidemiological research on caries in adolescents: A cross-sectional study. BMC Med. Res. Methodol. 2015, 15, 14. [CrossRef] [PubMed]

Publisher's Note: MDPI stays neutral with regard to jurisdictional claims in published maps and institutional affiliations.

(C) 2020 by the authors. Licensee MDPI, Basel, Switzerland. This article is an open access article distributed under the terms and conditions of the Creative Commons Attribution (CC BY) license (http://creativecommons.org/licenses/by/4.0/). 